\title{
New MIMO Antenna with Filtration for the Future Multiuser Systems in Satellite Communications
}

\author{
Chaker Essid $\left(\mathbb{D},{ }^{1}\right.$ Chafai Abdelhamid $\left(\mathbb{D},{ }^{2}\right.$ Faris. A. Almalki $\mathbb{D}^{3},{ }^{3}$ Obaid Ali $\mathbb{D},{ }^{4}$ \\ and Hedi Sakli $\mathbb{D}^{2,5}$ \\ ${ }^{1}$ SERCOM Laboratory, Tunisia Polytechnic School, University of Carthage, La Marsa 2078, Tunisia \\ ${ }^{2}$ MACS Laboratory, LR16ES22, National Engineering School of Gabes, University of Gabes, Gabes 6029, Tunisia \\ ${ }^{3}$ Department of Computer Engineering, College of Computers and Information Technology, Taif University, P.O. Box 11099, \\ Taif 21944, Saudi Arabia \\ ${ }^{4}$ Ibb University, Department of Computer Science \& Information Technology, Ibb, Yemen \\ ${ }^{5}$ EITA Consulting, 5 rue du Chant des Oiseaux, Montesson 78360, France
}

Correspondence should be addressed to Obaid Ali; obaid.alii2016@gmail.com

Received 4 December 2021; Revised 11 January 2022; Accepted 27 January 2022; Published 24 February 2022

Academic Editor: Issa Elfergani

Copyright (C 2022 Chaker Essid et al. This is an open access article distributed under the Creative Commons Attribution License, which permits unrestricted use, distribution, and reproduction in any medium, provided the original work is properly cited.

This paper emphasizes the function of the split ring resonator (SRR) within the design of ultra-wideband (UWB) antennas. We presented an antenna that belongs to the category of UWB antenna with two rejected bands based on square SRR. At first, we presented a UWB antenna. This antenna is designed to operate in the band 2.3-11.5 GHz. Then, with the integration of two SRR cells, we were capable of filtering the bands $3.7-3.9 \mathrm{GHz}$ and $8.7-8.9 \mathrm{GHz}$ without losing the UWB characteristics outside these rejected bands. Next, to ensure the proper performance of the MIMO system, we studied the use of metamaterials in the design of MIMO (Multiple-Input Multiple-Output) antennas for miniaturization and antenna performance.

\section{Introduction}

The performance of microwave circuits and devices is directly related to the intrinsic properties of the materials of manufacture. In addition, cost and integration constraints require intrinsic properties that are more attractive than those of conventional materials. The arrival of a new category of innovative materials, called "metamaterials," has broken the laws of physics dealing with wave systems [1]. This prompted the scientific community to study the possibility of breaking technological limits by exploiting the unnatural properties of these metamaterials. Indeed, the new attractive properties of metamaterials have already opened up a promising avenue for designers of microwave components.

Research work on these new materials has intensified in recent years, thanks in particular to progress both in electromagnetic modeling and in the mastery of technological production processes $[2,3]$. The path to the development of these new materials remains particularly interesting, even though they require suitable studies to be effectively used with microwave narrowband devices. The main drawback of UWB antennas is the partition of their frequency bands with existing narrowband systems such as WLAN and WiMAX due to their wideband characteristics. Therefore, it is important to eliminate interference with neighboring communication systems by using filtering to prevent the transmission or reception of an unwanted signal in a communication system [4]. To do this, the antenna must be able to play the role of a band-cut filter. To meet such a requirement, various ultra-wideband filtered band antennas have been designed by adding slits or stray elements to or near the radiating element [5-7]. The use of metamaterial structures such as the split ring resonator seems to be a very promising solution to meet these needs due to their extraordinary properties. A row of SRR has the filtering property, and once they are properly polarized, they can perfectly prevent signal propagation, thus providing an 
effective way to reject a frequency band near its resonant frequency [8-10]. For microarray antennas, it is possible to insert the SRR into the radiating element, the ground plane, or the power line [11-13] to obtain the rejected band function. The SRR can also be placed close to the radiant element or power line $[14,15]$. A microband line loaded with SRRs, therefore, shows a tape stop feature, and to improve the coupling, the distance between the line and the rings should be as small as possible.

Based on the filter model studied by [16], a novel UWB antenna structure is designed with two square split ring resonator cells inserted close to the feedline to provide frequency filtering matching WiMAX and WLAN applications in the frequency bands (3.6-3.8) GHz and (8.7-8.9) GHz. First, we will design a microband antenna working in the band defined by the FCC. The logical follow-up of our methodological approach corresponds to designing two SRR unit cells whose resonance frequencies are well following the WiMAX and WLAN applications. Next, we will study the association of the microband antenna with each SRR cell. The final step is to study the association of the microband antenna with the two SRR cells, the purpose of which is to design a UWB antenna with two rejected frequency bands.

For each simulated antenna structure, the position of the cell along the supply line and their orientation is studied by intensive parametric studies to determine the optimal position and orientation of the SRR cell to ensure better electromagnetic coupling in the field near the microribbon line. We conclude the paper by studying a solution based on the use of metamaterials that minimize or stop the diffusion of surface waves, thus decreasing the mutual coupling in an MIMO antenna that has two rejected tapes.

\section{Antenna Designing}

We initially started our design with a classic square printed antenna fed through a microstrip line. The choice of the supply line is based on the fact that this line must have a characteristic impedance of $50 \Omega$ and be suitable for a very large band. The geometric structure of the antenna consists of patches printed on the upper face of the FR4 type substrate. The ground plane is a partial plane printed on the lower surface of the substrate.

We made our choice on the FR4 epoxy substrate, its relative dielectric constant is 4.4 , and its dissipation factor $(\tan \delta)$ is 0.02 . This choice can be justified by the reason of its availability in our lab. Regarding the height of the substrate, it is $h=1.6 \mathrm{~mm}$. The antenna is electromagnetically powered by a microstrip line. The used ground plane is indeed a partial plan. The values of the parameters calculated for the microstrip line are given in Table 1.

Then, the dimensions of the rectangular patch can be determined using the analytical expressions presented in [17].

The modulus of the reflection coefficient of the initial patch is less than $-10 \mathrm{~dB}$ for frequencies in the $2.8-4.3 \mathrm{GHz}$ band and also in the $10.6-11.9 \mathrm{GHz}$ band, but in the $4.3-10.6 \mathrm{GHz}$ band, we note that the reflection coefficient of the module is greater than $-10 \mathrm{~dB}$. Therefore, this patch antenna is not well suited to the entire frequency band studied. In the second step, we adjusted the antenna with geometric modifications by introducing notches on the truncated patch at the four corners in order to extend the field of application and thus cover a wide bandwidth [18-20]. Figure 1 shows the dimensions and shape of the initial antenna consisting of a rectangular copper antenna. $\mathrm{Lp}$ and $\mathrm{Wp}$ are, respectively, the length and the width of the patch of antenna. The final UWB microstrip antenna that we propose is based on a simple shape as shown schematically in Figure 2. The antenna is designed on an epoxy FR-4 type. The ground plane and the radiating element have a thickness of $t=0.035 \mathrm{~mm}$. A narrowband relative to an ultra-wideband antenna is obtained for our initial antenna. Thus, in order to overcome the problem of its bandwidth, which was initially narrow as illustrated in Figure 3, we are making some modifications.

Our major concern about fulfilling the requirements of our goal is to succeed in expanding bandwidth. After parametric studies, the desired structure presented in Figure 4(c) was achieved. The design progress of the antenna, from the single square patch to our proposed antenna, is shown in Figure 3.

Figure 5 clarifies the effect of each variation on the coefficient of reflection reaching the final antenna; we want to show by this comparison the influence of these modifications on the attitude of the antenna. We notice an improvement in terms of adaptation by cutting a bevel on the corners of the antenna (Figure 3(b)), with a minimal value of about $-32 \mathrm{~dB}$ and a significant decrease in the S11 level by performing the inverted $M$ slot while widening the bandwidth. The simulation results of the reflection coefficient S11 clearly show an adaptation in the band 2.6-11.90 GHz $(\mathrm{S} 11 \leq$ $-10 \mathrm{~dB}$ ), with such a band of over $127 \%$. We, therefore, deduce that the modifications led us to a good structure of UWB. Figure 2 illustrates the final geometry of our antenna.

The various antenna dimensions optimized for operation on wideband from 2.6 to $11.9 \mathrm{GHz}$ are listed in Table 2 .

Figure 6 shows the monopole antenna's radiation pattern in planes $\mathrm{E}$ and $\mathrm{H}$ at frequency $6.0 \mathrm{GHz}$, where one can observe an omnidirectional beam to gain in the order of $4.5 \mathrm{dBi}$.

Figure 7 confirms that our antenna's efficiency is high. Its value surpasses $82 \%$ over the entire operating band. This implies that nearly all of the injected energy into the antenna is radiated.

\section{Results and Discussions}

For a good validation of the proposed design, a prototype of an antenna is manufactured and measured. Figure 8 shows the antenna as manufactured following the above parameters.

The S-parameters of the antenna were calculated using an Agilent Network Analyzer Keysight N5230A PNA-L $(300 \mathrm{kHz}$ to $20 \mathrm{GHz})$. These values are shown in Figure 9. By matching the measured and simulated results, we can observe that there is a small frequency shift. This can be the cause of some factors like cable loss, loss of SMA connector, and radiation limits during the measurement procedure. The 
TABLe 1: Basic microstrip line parameters.

\begin{tabular}{lcccc}
\hline Parameters & $\mathrm{W} f(\mathrm{~mm})$ & $\mathrm{h}(\mathrm{mm})$ & $\varepsilon_{\mathbf{r}}$ & $\mathrm{t}(\mathrm{mm})$ \\
\hline Values & 3.01 & 1.6 & 4.4 & 0.035 \\
\hline
\end{tabular}

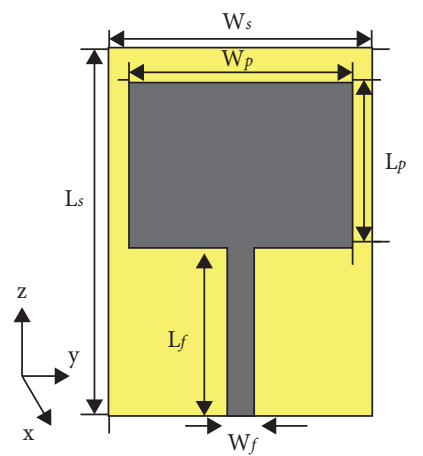

(a)

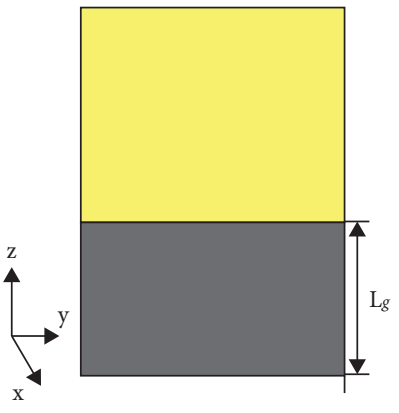

(b)

Figure 1: (a) Front view of the initial antenna and (b) bottom view of the initial antenna.

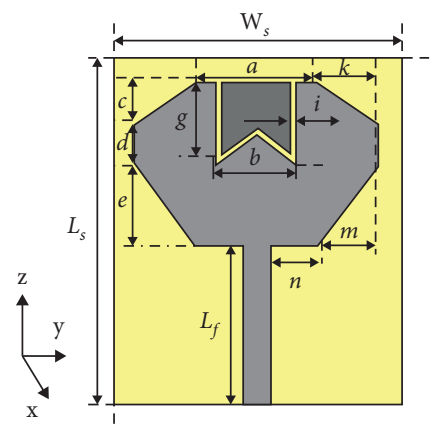

(a)

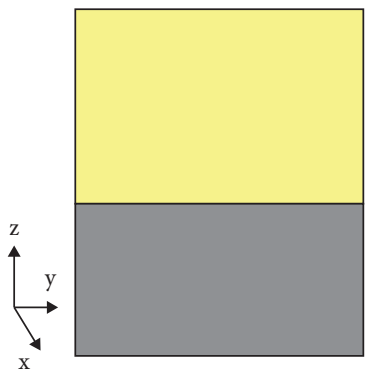

(b)

Figure 2: (a) Front view of the proposed antenna and (b) bottom view of the proposed antenna.

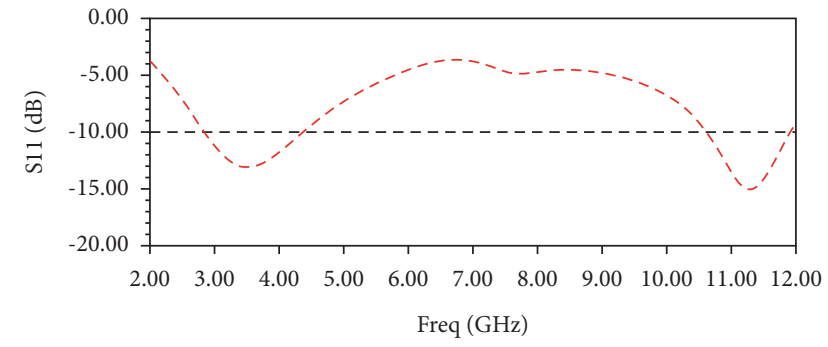

FIGURE 3: Reflection coefficient as a function of the frequencies of the basic square antenna.

proposed MIMO antenna's calculated frequency band is in the range of $2.1-12 \mathrm{GHz}$ with $\mathrm{S} 11<-10 \mathrm{~dB}$.

The antenna was put in an anechoic chamber (Figure 10) to analyze and measure its radiation. Figure 11 shows this measured radiation pattern in the $\mathrm{E}$ and $\mathrm{H}$ plane at the $6 \mathrm{GHz}$ frequency, where an omnidirectional beam with a gain of the order of $4.5 \mathrm{dBi}$ can be well observed. On the

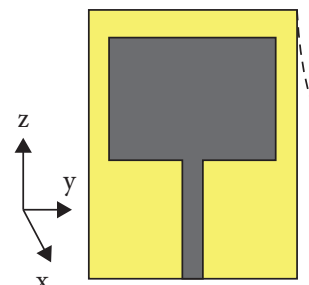

(a)

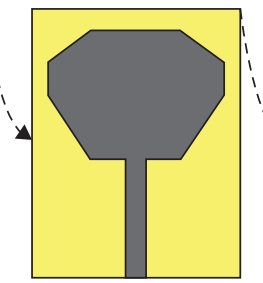

(b)

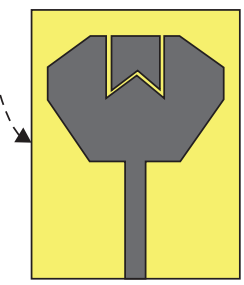

(c)
FIGURE 4: Design progress of the proposed UWB antenna.

other hand, a satisfactory agreement between the two simulation results and those of the measurement is noticed in a far field.

\section{Design of SRR Unit Cells}

In this part of our paper, we will design two square SRR unit cells, operating in frequencies corresponding to well-defined bands (WiMAX and X-band). 


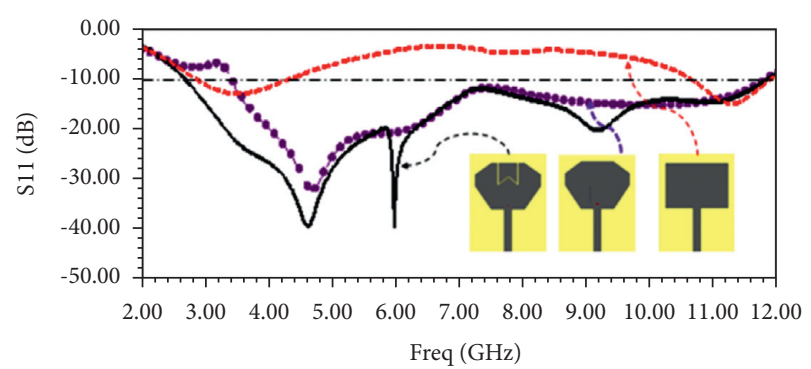

Figure 5: The base antenna's reflection coefficient, the four-corner truncated antenna, and the final antenna.

TABLE 2: Different values and parameters of the antenna.

\begin{tabular}{lccc}
\hline Parameters & Values & Parameters & Values \\
\hline$W_{\mathrm{S}}$ & 30 & hs & 1.6 \\
$\mathrm{Ls}$ & 38 & $\mathrm{Lf}$ & 17 \\
$\mathrm{Wp}$ & 17 & $\mathrm{Wf}$ & 3.01 \\
$L_{\mathrm{p}}$ & 25 & $e$ & 8.5 \\
$a$ & 12.5 & $d$ & 4.25 \\
$k$ & 6.25 & $c$ & 4.25 \\
$n$ & 4.87 & $\mathrm{Lg}$ & 15.6 \\
$m$ & 6.37 & $b$ & 7 \\
$g$ & 0.5 & $I$ & 0.5 \\
\hline
\end{tabular}

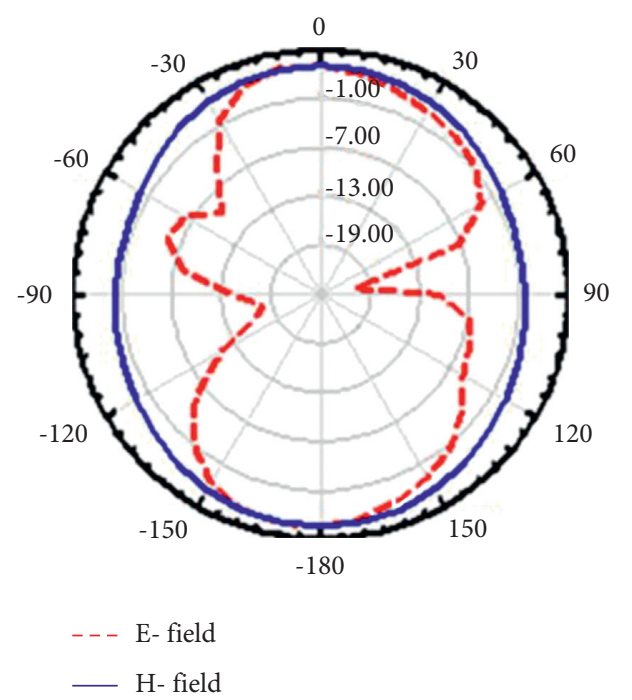

Figure 6: Antenna radiation diagram simulated at the frequency of $6.0 \mathrm{GHz}$ in planes $\mathrm{H}\left(\right.$ or $\mathrm{phi}=0^{\circ}$ ) and $\mathrm{E}\left(\right.$ or $\mathrm{phi}=90^{\circ}$ ).

Throughout our study, we will use the S-parameterbased method to design and analyze the performance of metamaterial unit cells. The overall cell size should be less than the wavelength $(\mathrm{d} \lambda)[21]$ (around $\lambda 0 / 11$ for our case). To do this, we will proceed according to the methodological approach of designing unitary cells. Figure 12 shows the studied resonators. The first SRR is sized for operation in the band of $8.6-8.9 \mathrm{GHz}$; it consists of two concentric and spaced rings, whose outer ring contains a slot. The

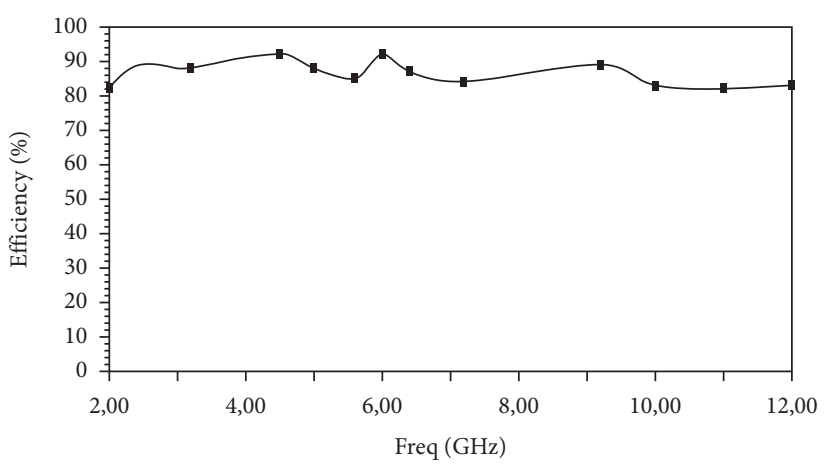

Figure 7: The efficiency of the proposed antenna.

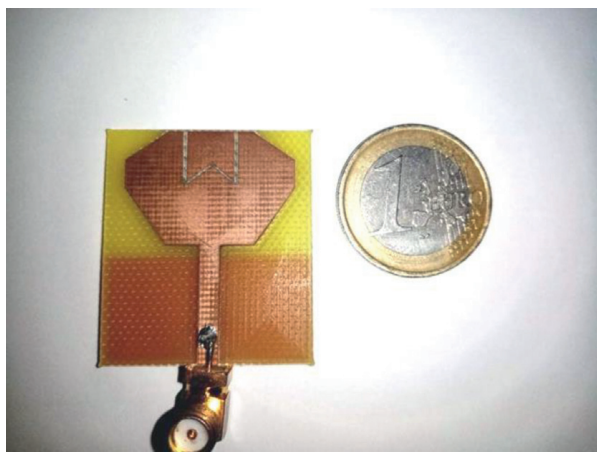

Figure 8: Prototype of the proposed antenna.

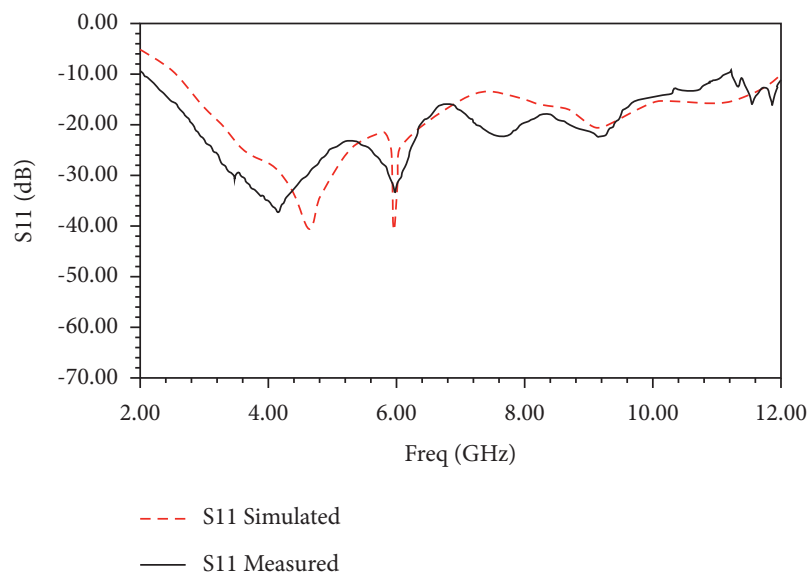

Figure 9: Reflection coefficient of the proposed antenna.

dimensions of the second resonator are optimized so that it can work in the band 3.6-3.8 GHz; it consists of a single ring with a cut deposited on the dielectric substrate. All these resonators are copper and deposited on a dielectric substrate of type FR4-epoxy permittivity 4.4 and thickness $1.6 \mathrm{~mm}$, the width of each unit cell is noted by $\mathrm{Wi}$, the width of the copper track is noted by $\mathrm{Li}$, the spacing between two concentric rings is noted by $\mathrm{Gi}$, and the width of the cutting of the rings is noted by Si. All geometric parameters of these SRRs are grouped in Table 3.

Figures 13 and 14 represent transmission (S21) and the coefficients of reflection (S11) in $\mathrm{dB}$ following the simulation 


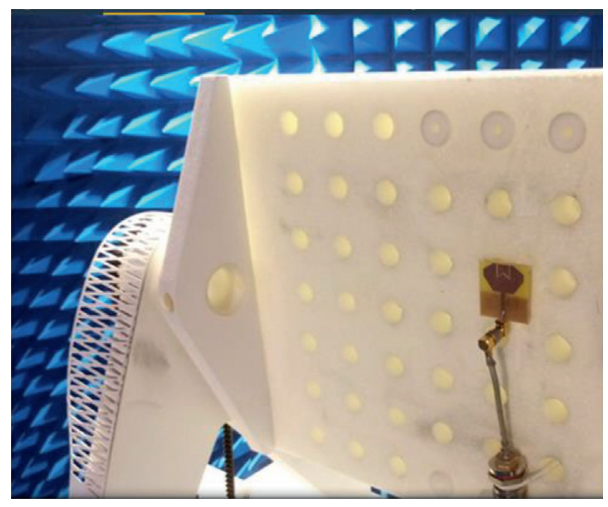

Figure 10: Device to measure the antenna put in the anechoic chamber.

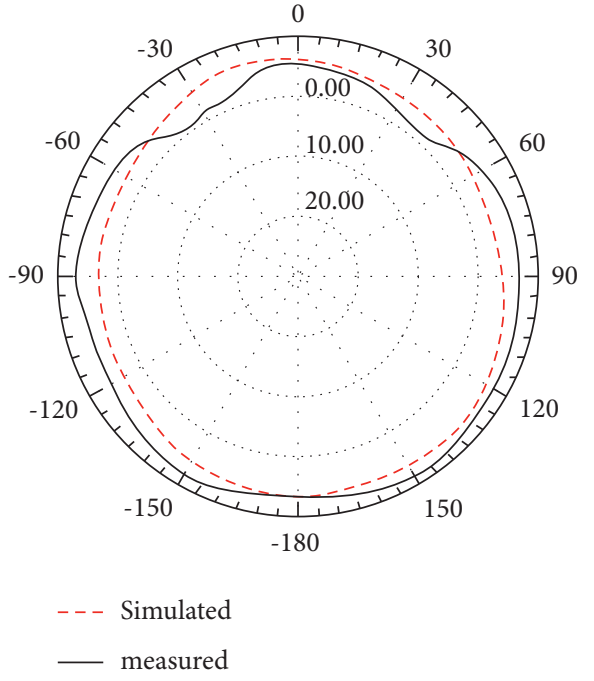

(a)

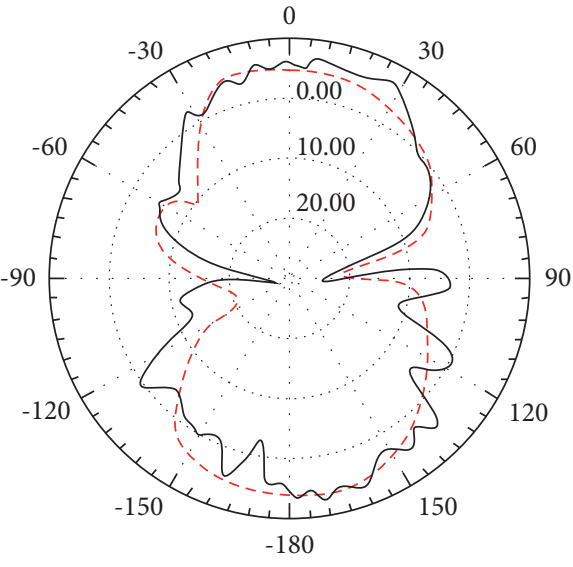

- - - Simulated

measured

(b)

FIGURE 11: Monopole antenna radiation pattern measured and simulated at the frequency of $6.0 \mathrm{GHz}$ : (a) in the $\mathrm{H}$ plane and (b) E plane.

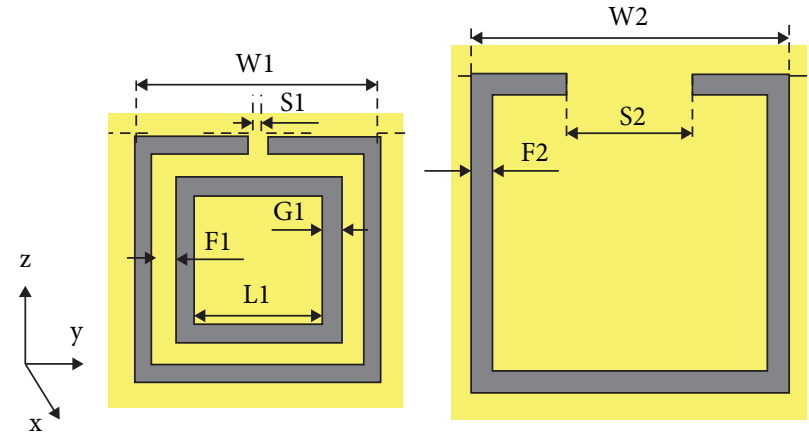

FIGURE 12: Configuration of the square SRR cell printed on an FR4 substrate.

TABLE 3: Different values and parameters of the SRRs.

\begin{tabular}{|c|c|c|c|c|c|}
\hline SRR1 & $\mathrm{W} 1(\mathrm{~mm})$ & $\mathrm{S} 1(\mathrm{~mm})$ & $\mathrm{F} 1(\mathrm{~mm})$ & $\mathrm{G} 1(\mathrm{~mm})$ & $\mathrm{L} 1(\mathrm{~mm})$ \\
\hline Values & 2.7 & 0.2 & 0.2 & 0.25 & 1.8 \\
\hline SRR2 & $\mathrm{W} 2(\mathrm{~mm})$ & $\mathrm{S} 2(\mathrm{~mm})$ & $\mathrm{F} 2(\mathrm{~mm})$ & & \\
\hline Values & 7 & 2.8 & 0.6 & & \\
\hline
\end{tabular}


of the two SRRs cells shown in Figure 12. The results of the simulation of the S-parameters of two cells show, respectively, a cut bandwidth behavior around the frequency of $8.85 \mathrm{GHz}$ and $3.7 \mathrm{GHz}$. An S11 tends towards $0 \mathrm{~dB}$ with an attenuated transmission coefficient (S21) of the order of $-18 \mathrm{~dB}$ and $-14.5 \mathrm{~dB}$, respectively, for cell 1 and cell 2 . These results confirm a forbidden band phenomenon around the resonance frequency of each metamaterial cell (i.e., there is no transmission around the resonance frequency of each unit cell).

\section{UWB Antenna Associated with SRR Unit Cells}

In this step of our paper, the study focuses on the use of SRRs previously designed with the environment of the UWB antenna, whose aim is to design a UWB antenna with two rejected bands. This is done by placing each resonator close to the power line while performing parametric studies of the resonator orientation and position along the power line to obtain the optimal position, in which the SRR resonator will be well excited. To avoid interference with the WiMAX system from 3.6 to $3.9 \mathrm{GHz}$, the first SRR resonator is placed near the power line of the previously designed UWB antenna; its position (d1) is varied throughout the power line to obtain the best position; the aim is to satisfy the conditions of excitation of the resonator since notch filtering can be achieved in the bandwidth of the UWB antenna around the resonant frequency of the SRR cells.

The best result was obtained in our case with the position of the $d 1=7 \mathrm{~mm}$. The second SRR resonator is also placed near the line at the distance $d 2=13.55 \mathrm{~mm}$, to attenuate the interference signals around $9 \mathrm{GHz}$ and reduce their impact on the UWB system. To avoid interference with the WiMAX system from 3.6 to $3.9 \mathrm{GHz}$, the first SRR resonator is placed near the power line of the previously designed UWB antenna, its position $(\mathrm{d} 1)$ is varied throughout the power line to obtain the best position, and the aim is to satisfy the conditions of excitation of the resonator. The best result was obtained in our case with the position of the $d 1=7 \mathrm{~mm}$. The second SRR resonator is also placed near the line at the distance $d 2=13.55 \mathrm{~mm}$, to attenuate the interference signals around $9 \mathrm{GHz}$ and reduce their impact on the UWB system. The geometry of these two structures is shown in Figure 15. The space between the resonators and the supply line is fixed to $0.2 \mathrm{~mm}$; the choice of this value is due to the technological constraints of realization.

Figures 16 and 17 show the reflection coefficients of each UWB antenna structure associated with an SRR resonator, the two simulated structures show a rejected frequency band $(\mathrm{S} 11>-10 \mathrm{~dB})$, and these bands are identical to the prohibited bands of the previously studied SRRs cells.

\section{Rejected Dual-UWB Antenna}

The two SRRs, studied above, are placed in order to provide filtering for the two bands, namely, the WiMAX band $3.6-3.8 \mathrm{GHz}$ and the band from 8.7 to $8.9 \mathrm{GHz}$. The geometry of our antenna is well mentioned in Figure 18.

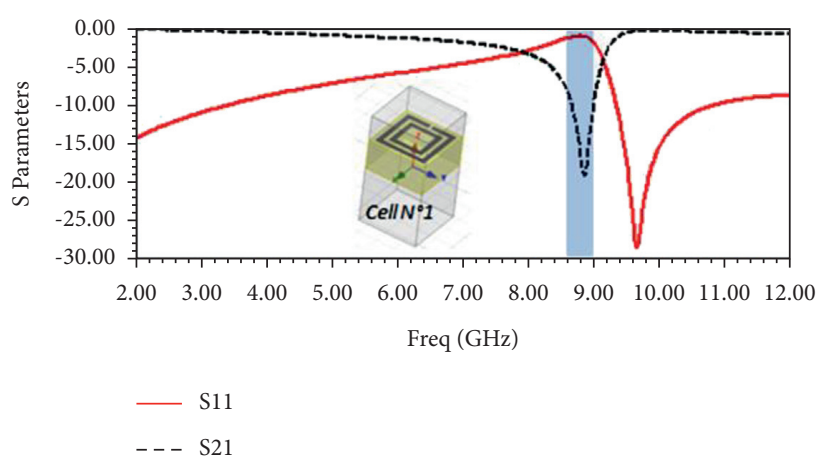

FIGURE 13: S-parameter (reflection and transmission coefficient) of SRR studied: cell $\mathrm{N}^{\circ} 1$.

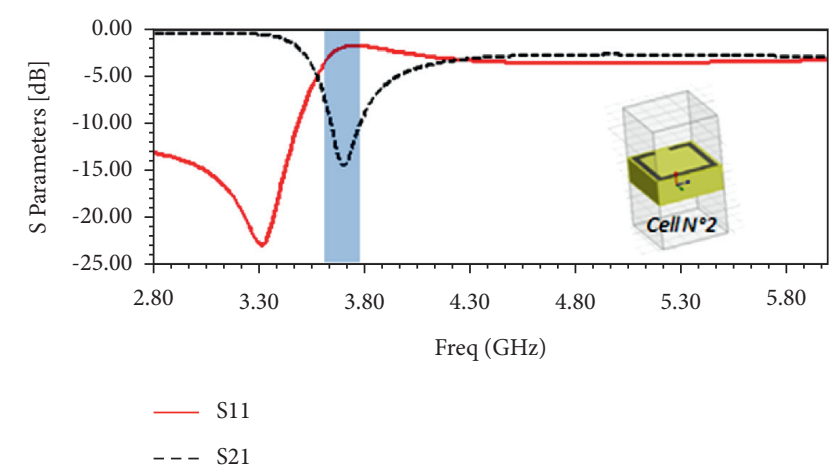

FIGURE 14: S-parameter (reflection and transmission coefficient) of SRR studied: cell $\mathrm{N}^{\circ} 2$.

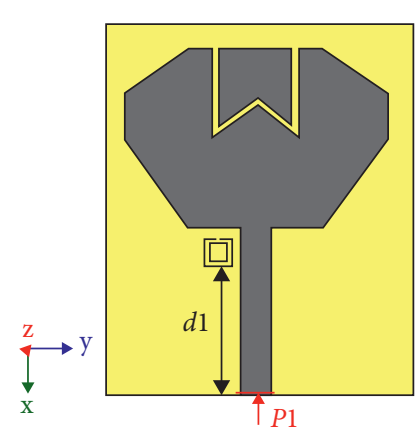

(a)

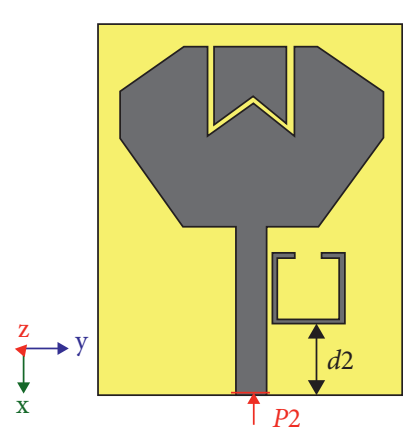

(b)
Figure 15: UWB antenna associated with (a) cell $\mathrm{N}^{\circ} 1$ and (b) cell $\mathrm{N}^{\circ} 2$.

Figure 19 presents the reflection coefficient's evolution as a function of frequency for the UWB antenna initially presented, as well as the two-band rejected antenna studies. The S-parameter simulation result shows that our antenna operates in the band (2.38-11.30) GHz (S11<-10 dB), except in the bands $(3.68-3.88) \mathrm{GHz}$ and $(80.7-8.95) \mathrm{GHz}$ where $\mathrm{S} 11=-2 \mathrm{~dB}$. Behavior band cutter around the resonance frequency of each SRR cell which results in two rejected bands is well noticed, the first band around the 3.7 $\mathrm{GHz}$ frequency with a $200 \mathrm{MHz}$ rejected band, and the 


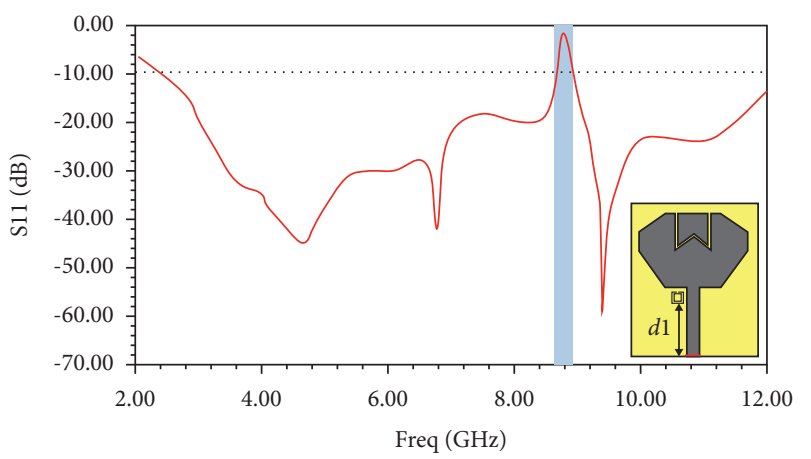

FIgURE 16: S-parameter S11 of the UWB antenna associated with cell $\mathrm{N}^{\circ} 1$.

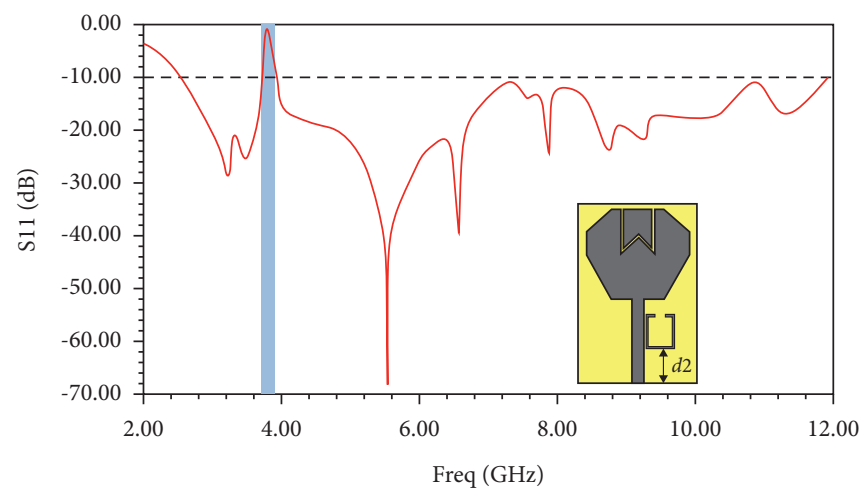

FIgURE 17: S-parameter S11 of the UWB antenna associated with cell $\mathrm{N}^{\circ} 2$.

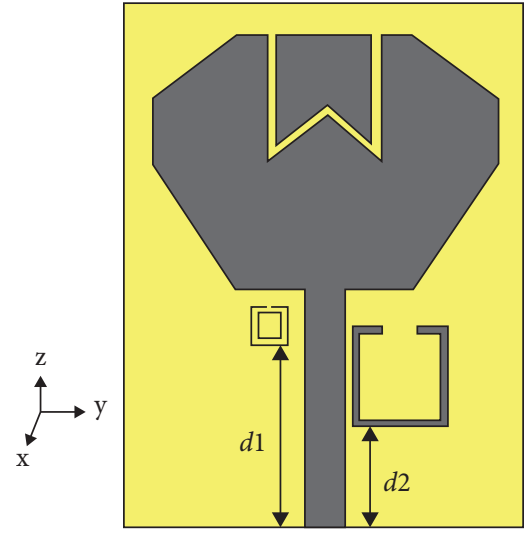

FIGURE 18: Configuration of the UWB antenna combined with an upstream filtering system with two switchable rejected bands.

second around the frequency $8.8 \mathrm{GHz}$ with a rejected band of $250 \mathrm{MHz}$. These two rejected bands are identical to those obtained in the previous case. We also note that these results clearly show that the integration of these SRR cells does not affect the adaptation of our antenna outside the two rejected bands.

They also showed a stable radiant performance of the device (antenna + filter) as shown in Figure 20, due to a decoupling between the filter device and the radiation device. Comparison of the simulated radiation diagrams of the

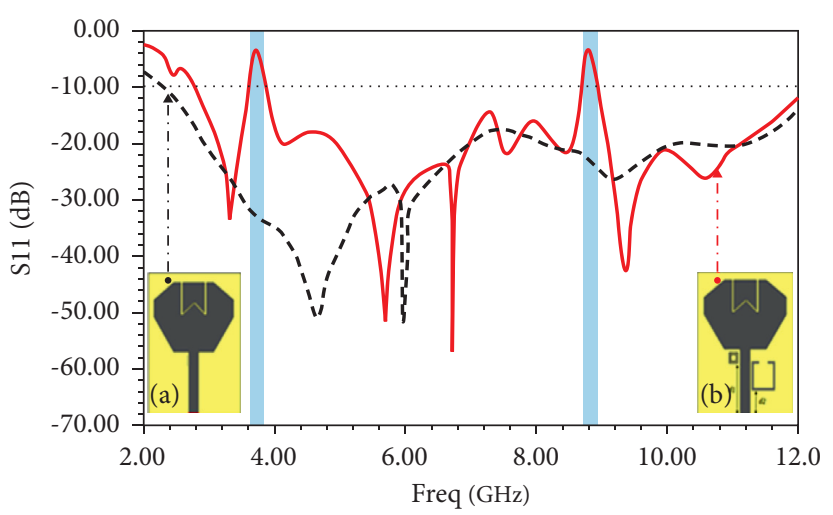

FIGURE 19: UWB antenna reflection coefficient S11: (a) with SRRs and (b) without SRRs.

antenna and the device (antenna + filter). All the results show a stable radiant performance with an omnidirectional beam and a gain of $4.5 \mathrm{dBi}$.

For the experimental validation of the antenna model in Figure 18, a mock-up is made as shown in Figure 21. The antenna's frequency characterization is then performed using the Agilent network analyzer N5230A. The results of measurement and simulation of the S-parameter S11 of the rejected band antenna are shown in Figure 22. The comparison of the simulation results with those of the 


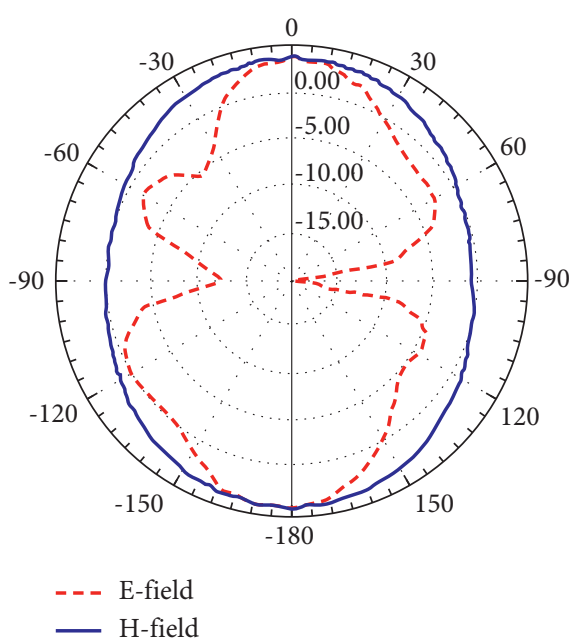

FIGURE 20: Device radiation diagram (monopoly antenna + filter) simulated at $6.0 \mathrm{GHz}$ frequency in $\mathrm{H}$ and $\mathrm{E}$ planes.

measurement shows a good satisfactory agreement in the first rejected frequency band; however, a gap between the results is noticed in the other band. This is surely due to uncertainties in manufacturing or sizing.

Furthermore, regarding the level of adaptation, the measurement results are better than those of the simulation.

\section{Reduction of Mutual Coupling Based on Metamaterials}

After studying the SRRs previously designed with the UWB antenna environment, these cells will be placed near the antenna whose purpose is to design a dual-UWB antenna. Then, we place two identical dual-band antennas spaced at a distance $d=5 \mathrm{~mm}$ (see Figure 23). The impact of a unitary SRR cell network between the two antennas side by side will be studied. So, for this purpose, a network of SRR cells composed of 7 SRRs cells is shown in Figure 24. We attempt to achieve an electromagnetic BlackBerry in order to ensure isolation on the flux and radiation interference from the proximity of the adjacent antenna. Then, using metamaterial, a method was proposed to stop or decrease the propagation of surface waves, thus lowering the mutual coupling in MIMO antennas.

\section{Isolation between Two MIMO Antennas}

Two power ports, port 1 and port 2, are shown in the structure of our two-element MIMO antenna (Figure 24). Figure 25 shows the coefficients of the simulated reflections (S11; S22) of our proposed MIMO antenna before the use of metamaterials and after it. It is observed from Figure 25 that the MIMO antenna's reflection coefficients with and without metamaterial are nearly identical to the entire working band initially presented and that each one of them is below $-10 \mathrm{~dB}$ on the desired band.

In the beginning, before the application of metamaterials to isolate the two antennas, the mutual coupling regarding

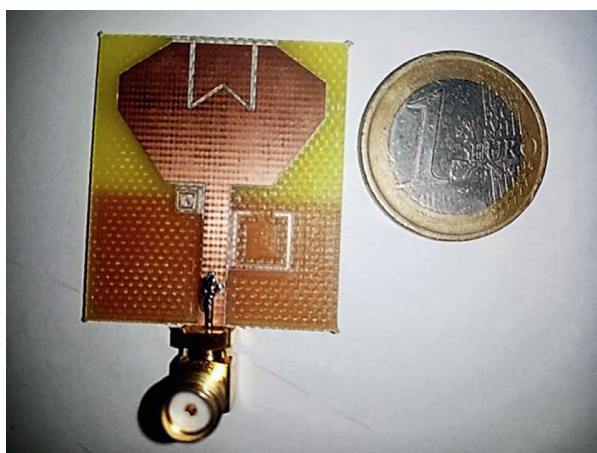

FIgURe 21: Prototype of the MIMO antenna mentioned in Figure 18.

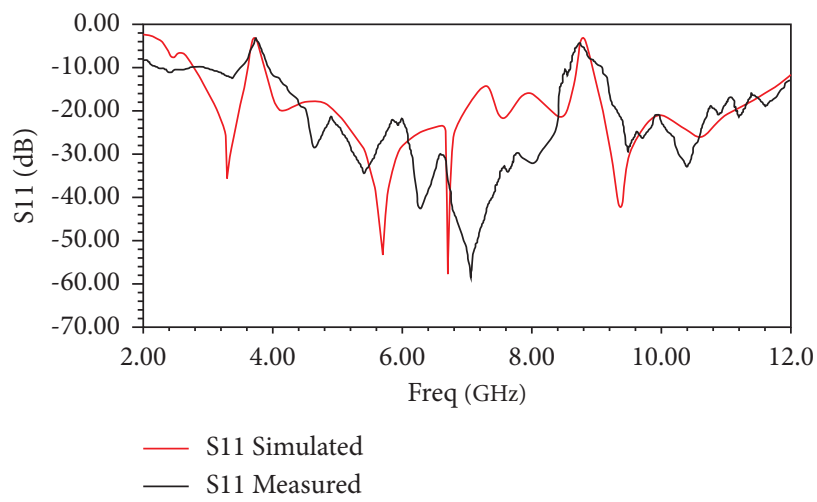

Figure 22: Proposed antenna: calculated and measured coefficient $S$ of the antenna.

the transmission coefficient measured at the frequency of $2.5 \mathrm{GHz}$ was $-10.8 \mathrm{~dB}$ and at a frequency of $11.7 \mathrm{GHz}$ was $-11.1 \mathrm{~dB}$ between the two antennas. With the coupling technique based on metamaterials used between the two antennas, we notice from Figure 26(a) significant improvement in the parameter S21 $(\mathrm{S} 21<-30 \mathrm{~dB})$ over our 


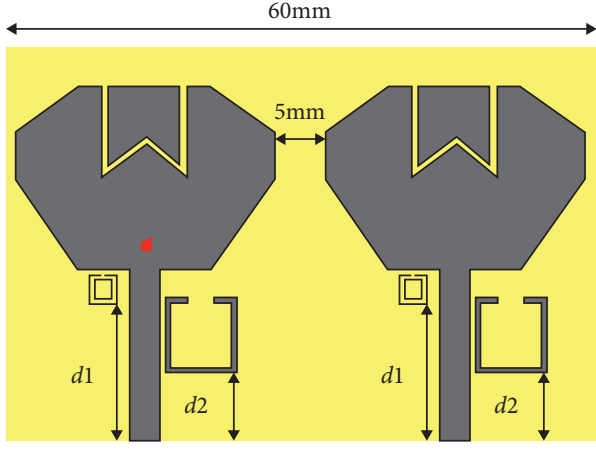

(a)

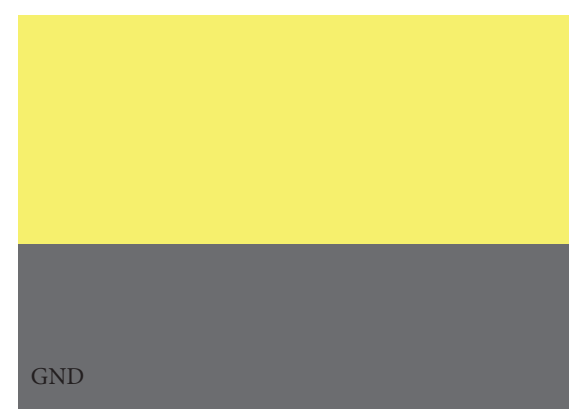

(b)

FIgURE 23: Structure of two antennas without SRRs: (a) front view and (b) bottom view.
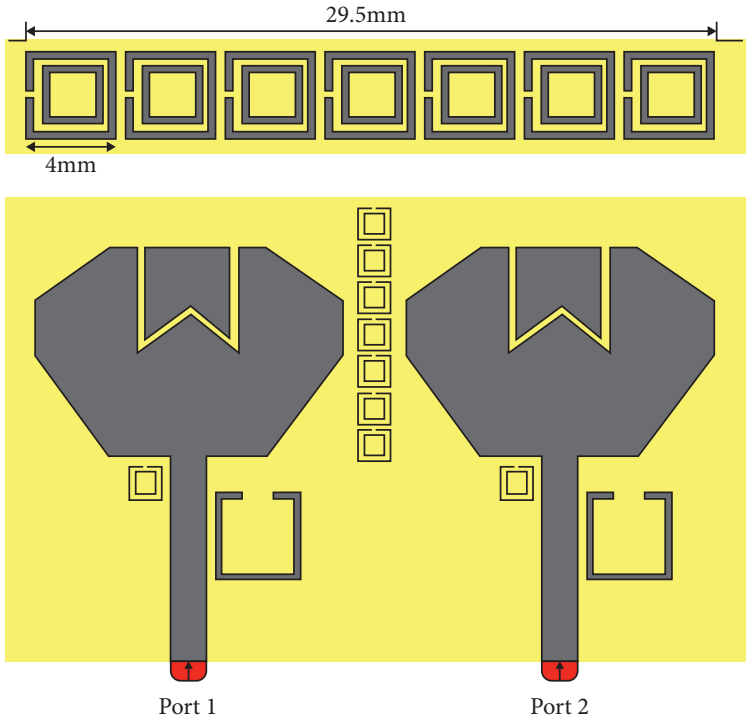

FIgURE 24: Antenna structure proposed with SRRs and unit cell chain architecture in front view.

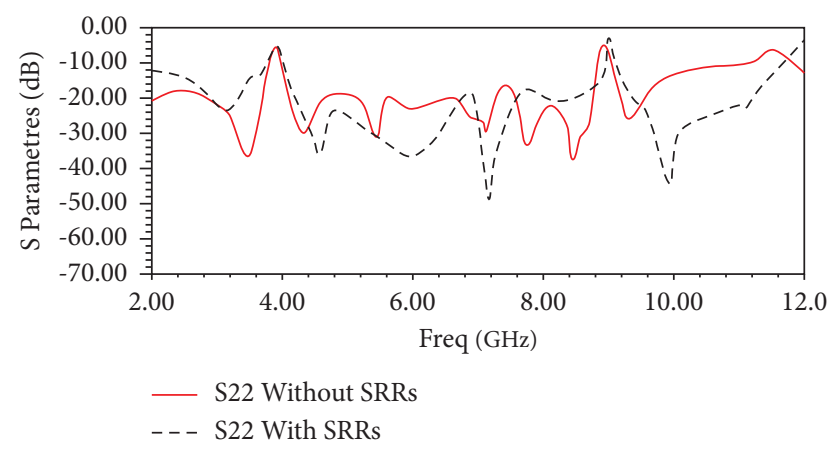

FIGURE 25: S22/S11 of the structure without and with SRRs.

entire operating band. The mutual coupling between the antennas is therefore significantly reduced. Thus, the requirement to have a mutual coupling less than $-20 \mathrm{~dB}$ is imposed, to maintain the performance of a MIMO system. Observing Figure 26, the transmission coefficients show good transmission quality with low power loss over the entire band. An isolation protection gain greater than $25 \mathrm{~dB}$ over the entire band is obtained. This is due to the isolation performance between the antennas. This structure implies an increase in the performance of MIMO system [22-32].

It is preferable to study the interferences in our MIMO system caused to near field radiation, the aim of which is to better understand the mutual coupling between the two antennas while analyzing the current distributions on the two elements. The simulated current distributions of antenna 1 at the $6 \mathrm{GHz}$ frequency are shown in Figure 27. Note here that when the port of the antenna $\mathrm{N}^{\circ} 1$ is energized, the port of the antenna $\mathrm{N}^{\circ} 2$ ends by a load of $50 \Omega$. In Figure 27(a), it can be seen that the surface current in the orifice of the exciting element 1 induces currents in the second element through the common ground plane. This generates a strong coupling translated by values of S-parameter S21. For MIMO antennas to function properly, they must be independent with a minimum of coupling; therefore, better isolation is necessary. One effective approach is to work on the MTM to limit the flow of current from one port to another, ultimately reducing the mutual coupling between the two ports. By energizing port 1, for example, the maximum current is on this one. It is then absorbed by the chain of SRRs cells. This proves that there is no (excessive) distribution of current from one to the other and therefore little or no current transfer between the two antennas and allows therefore reducing the coupling between ports, which leads to good mutual isolation. Indeed, we can confirm that significant isolation is ensured between the two antennas with metamaterials.

Figure 28 presents the results of the ECC correlation envelope obtained by simulation, which is calculated from the S-parameters as explained in the following relation [29]. The ECC, which is given by equation (1), is a very important factor in evaluating the diversity performance of the MIMO system.

$$
\mathrm{ECC}=\frac{\left|S_{11}^{*} S_{12}+S_{21}^{*} S_{22}\right|^{2}}{\left(1-\left|S_{11}\right|^{2}-\left|S_{21}\right|^{2}\right)\left(1-\left|S_{22}\right|^{2}-\left|S_{12}\right|^{2}\right)} .
$$

In a MIMO system, the diversity gain (DG) is a parameter that indicates that the signal-to-noise ratio (SNR) of the combined signal is enhanced over the signal-to-noise 


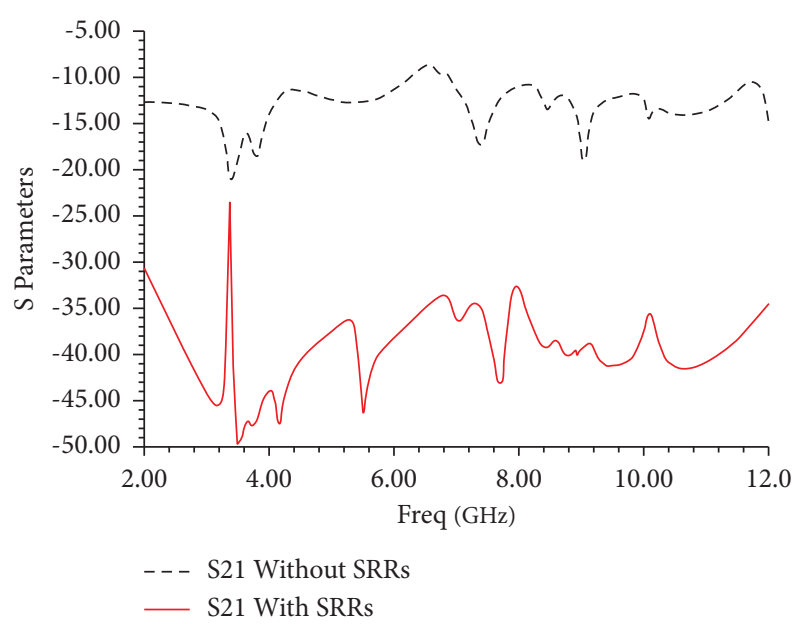

FIGURE 26: Isolation analysis of MIMO antennas with and without metamaterial.

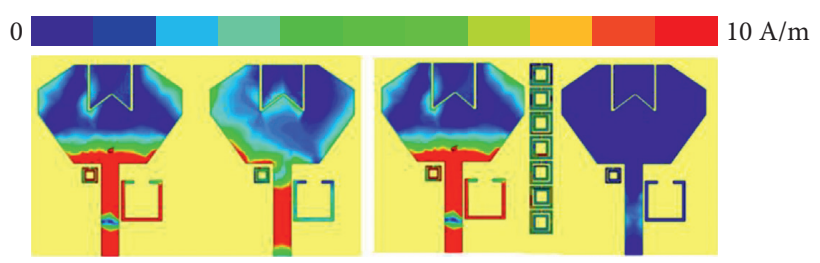

FIGURE 27: Surface currents on the radiating elements for the case of the excitation of port $\mathrm{N}^{\circ} 1$ with and without MTM.

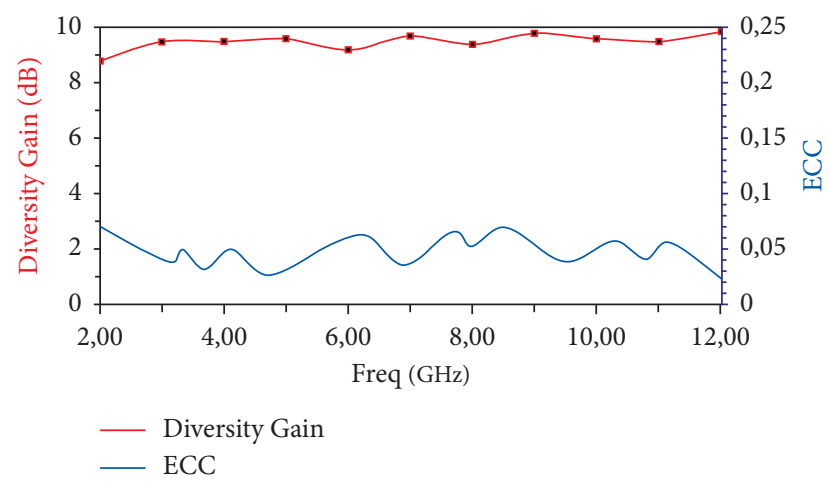

Figure 28: DG and ECC simulated from S-parameters.

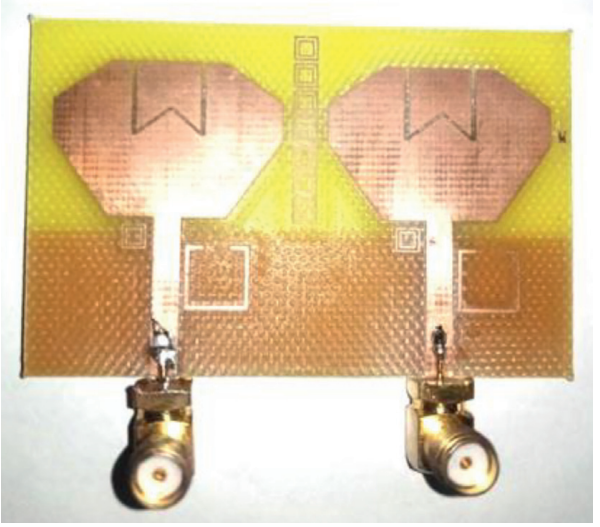

Figure 29: Photos of the manufactured antenna system.
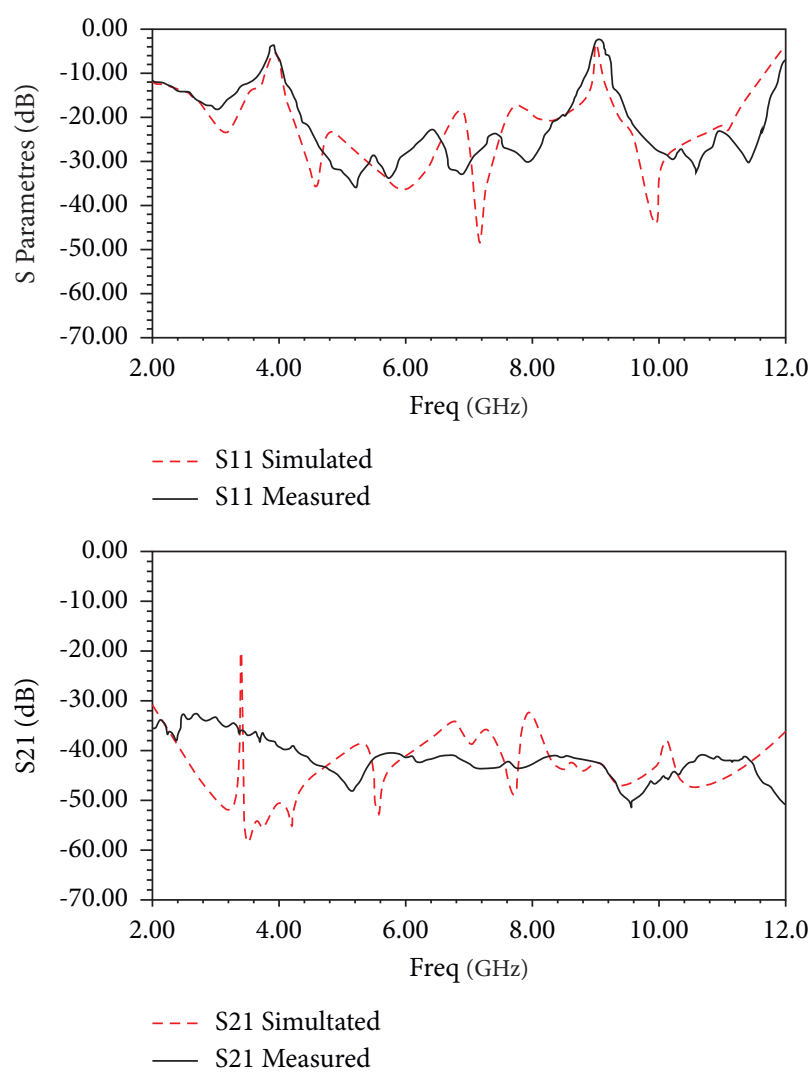

FIGURE 30: S-parameters of the structure with SRRs.

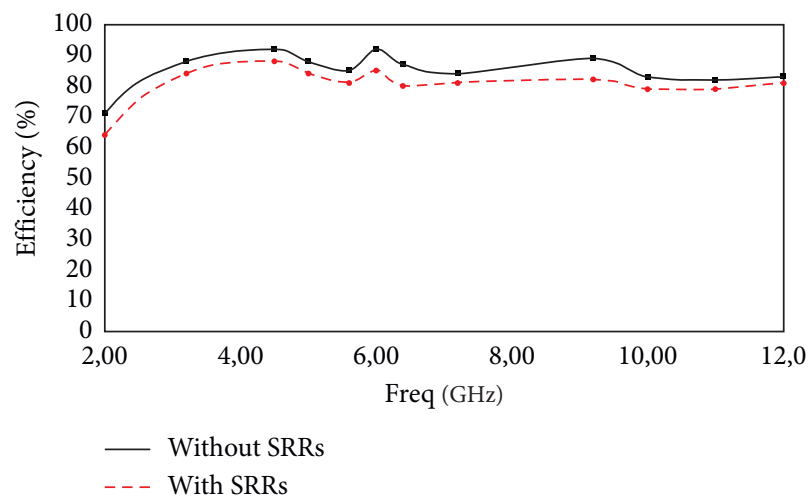

FIgURE 31: Total efficiency of each access with and without SRRs (only port 1 is displayed here).

ratio obtained by a single antenna. The diversity gain (DG) can be calculated as shown in equation (2) [29].

$$
D G=10 \sqrt{1-\left((E C C)^{2}\right)} .
$$

Therefore, the diversity performance of a link can be assessed using the envelope correlation coefficient, which indicates the independence of the received signals, while the diversity gain represents the improvement in the signal-tonoise ratio (SNR) of the combined relative signals versus the signal-to-noise ratio received on a single antenna, since the 
TABle 4: Difference between the MIMO antenna presented and the previous UWB-MIMO antennas.

\begin{tabular}{|c|c|c|c|c|c|c|}
\hline Ref. & Element number & Bandwidth $(\mathrm{GHz})$ & Dimensions $(\mathrm{mm} \times \mathrm{mm})$ & Gain $(\mathrm{dBi})$ & Radiation efficiency (\%) & ECC \\
\hline [21] & 1 & $3.11-17.51$ & $64 \times 64$ & 6 & ---- & ----- \\
\hline [22] & 1 & $2.1-16$ & $50 \times 30$ & $3.6-6$ & 81 & $<0,25$ \\
\hline [29] & 4 & $2.96-10.9$ & $43 \times 43$ & $2-6.1$ & 79 & $<0.1$ \\
\hline$[30]$ & 4 & $5-6.1$ & $60 \times 33$ & 7.6 & 84 & $<0.04$ \\
\hline Proposed antenna & 2 & $2-12.1$ & $48 \times 35$ & $2-8.2$ & 85 & $<0,07$ \\
\hline
\end{tabular}

diversity gain (DG) depends to a large extent on the ECC. Two parameters, which are the coupling between the elements and the overall efficiency of the antennas, have a considerable influence on the performance of the antenna systems. They are included in the calculation of the correlation coefficient and the diversity gain as mentioned. We notice that the ECC is very low and that the DG varies between 9 and $10 \mathrm{~dB}$ (Figure 28). DG is maximum or point or ECC is minimum on the operating band of our MIMO antenna.

For the antenna model's experimental validation of Figure 23, a mock-up is carried out as indicated in Figure 29. The frequency characterization of the antenna is then carried out using the Agilent N5230A Keysight PNA-L $300 \mathrm{kHz}$ to $20 \mathrm{GHz}$ network analyzer. The results of the measurement of the $\mathrm{S}$-parameters of the antenna carried out are displayed in Figure 30. The measured and simulated S-parameters of the antenna structure with and without SRR are in good agreement. The impedance bandwidth $(\mathrm{S} 11<-10 \mathrm{~dB})$ can cover the entire UWB $(2-12 \mathrm{GHz})$. The results of the simulations and those of the measurements also show a good agreement between them and prove that the proposed prototype is well suited with an isolation level of the order of $-34 \mathrm{~dB}$ over the entire UWB. It is noted here that the deviations are assigned to the manufacturing tolerance and to the loss of connectors. These results clearly show that this antenna is a fair candidate for MIMO operation in the UWB indicated previously.

Figure 31 represents the total efficiency of MIMO antenna with and without SRRs. We note that the total efficiency is between $80 \%$ and $90 \%$ over the entire frequency band of our MIMO antenna.

Table 4 presents a comparison between the proposed MIMO antenna and that in other related works. We notice that the proposed antenna exhibits better efficiency.

\section{Conclusion}

The main subject of this paper is the study and application of structures based on metamaterials. Our goal in this paper is to analyze and design metamaterials applied on the antennas to avoid interference with the WiMAX system and the $\mathrm{X}$-band and to increase the performances of the antennas in terms of isolation technique between the different elements constituting the MIMO antenna. The results obtained show that these resonators can perfectly prevent the signal propagation near its resonant frequencies, do not affect it elsewhere, and offer advantages such as weight reduction and bulk, which are beneficial for their integration in telecommunication systems.

\section{Data Availability}

The data used to support the findings of this study are available from the corresponding author upon request.

\section{Conflicts of Interest}

The authors declare no conflicts of interest.

\section{Acknowledgments}

The authors are grateful to the Deanship of Scientific Research at Taif University, Saudi Arabia, for funding this project through Taif University Researchers Supporting Project no. TURSP-2020/265.

\section{References}

[1] H. Lalj, H. Griguer, and M. h. Drissi, "Very compact bandstop filters based on miniaturized complementary metamaterial resonators," Wireless Engineering and Technology, vol. 4, no. 2, pp. 101-104, 2013.

[2] G. Gao, B. Hu, L. He, S. Wang, and C. Yang, "Investigation of A Reconfigurable dual notched UWB antenna by conceptual circuit model and time-domain characteristics," Microwave and Optical Technology Letters, vol. 59, no. 6, pp. 1326-1332, 2017.

[3] R. Boopathi Rani and S. K. Pandey, "A CPW-fed circular patch antenna inspired by reduced ground plane and CSRR slot for UWB applications with notch band," Microwave and Optical Technology Letters, vol. 59, no. 4, pp. 745-749, 2017.

[4] M. S. Sharawi, S. K. Podilchak, M. T. Hussain, and Y. M. M. Antar, "Dielectric resonator based MIMO antenna system enabling millimetre-wave mobile devices," IET Microwaves, Antennas \& Propagation, vol. 11, no. 2, pp. 287-293, 2017.

[5] H. S. Singh and S. Kalraiya, "Design and Analysis of a compact WiMAX and WLAN band notched planar monopole antenna for UWB and bluetooth applications," International Journal of $R F$ and Microwave Computer-Aided Engineering, vol. 28, no. 9, 2018.

[6] S. Cumali and N. Tayfun, "Design and characterization of a resonator-based metamaterial and its sensor application using microstrip technology," Optical Engineering, vol. 55, p. 27107, 2016.

[7] S. S. Al-Bawri, "Metamaterial cell-based superstrate towards bandwidth and gain enhancement of quad-band CPW-fed antenna for wireless applications," Sensors (MDPI), vol. 20, no. 2, pp. 1-14, 2020.

[8] A. Iqbal, O. A. Saraereh, A. W. Ahmad, and S. Bashir, "Mutual coupling reduction using F-shaped stubs in UWB-MIMO antenna," IEEE Access, vol. 6, pp. 2755-2759, 2018.

[9] J. Ghosh, S. Ghosal, D. Mitra, and S. R. Bhadra Chaudhuri, "Mutual coupling reduction between closely placed 
microstrip patch antenna using meander line resonator," Progress In Electromagnetics Research Letters, vol. 59, pp. 115-122, 2016.

[10] S. Zhang, B. K. Lau, A. Sunesson, and S. He, "Closely-packed UWB MIMO/diversity antenna with different patterns and polarizations for USB dongle applications," IEEE Transactions on Antennas and Propagation, vol. 60, no. 9, pp. 4372-4380, 2012.

[11] A. Suntives and R. Abhari, "Miniaturization and isolation improvement of a multiple-patch antenna system using electromagnetic bandgap structures," Microwave and Optical Technology Letters, vol. 55, no. 7, pp. 1609-1612, 2013.

[12] F. G. Zhu, J. D. Xu, and Q. Xu, "Reduction of mutual coupling between closely packed antenna elements using defected ground structure," Electronics Letters, vol. 45, no. 12, pp. 601-602, 2012.

[13] G. Adamiuk, S. Beer, W. Wiesbeck, and T. Zwick, "Dualorthogonal polarized antenna for UWB-IR technology," IEEE Antennas and Wireless Propagation Letters, vol. 8, pp. 981984, 2009.

[14] M. S. Khan, A.-D. Capobianco, S. M. Asif, D. E. Anagnostou, R. M. Shubair, and B. D. Braaten, "A compact CSRR-enabled UWB diversity antenna," IEEE Antennas and Wireless Propagation Letters, vol. 16, pp. 808-812, 2017.

[15] A. K. Verma, R. Nakkeeran, and R. K. Vardhan, "Design of $2 \times 2$ single-sided wrench shaped UWB MIMO antenna with high isolation," in Proceedings of the IEEE International Conference on Circuit, Power and Computing Technologies, ICCPCT, Kumaracoil, India, March 2016.

[16] H. Lalj, H. Griguer, and M. h. Drissi, "Design of reconfigurable band notches antenna for cognitive radio applications," Wireless Engineering and Technology, vol. 5, no. 3, pp. 99-105, 2014.

[17] C. A. Balanis, Antenna Theory,Analysis and Design, John Wiley \& Sons, Hoboken, NJ, USA, 2005.

[18] J. Tao and Q. Feng, "Compact UWB band-notch MIMO antenna with embedded antenna element for improved band notch filtering," Progress In Electromagnetics Research C, vol. 67, pp. 117-125, 2016.

[19] L. Liu, S. W. Cheung, and T. I. Yuk, "Compact MIMO antenna for portable UWB applications with band-notched characteristic," IEEE Transactions on Antennas and Propagation, vol. 63, no. 5, pp. 1917-1924, 2015.

[20] P. Gao, S. He, X. Wei, Z. Xu, N. Wang, and Y. Zheng, "Compact printed UWB diversity slot antenna with $5.5-\mathrm{GHz}$ band-notched characteristics," IEEE Antennas and Wireless Propagation Letters, vol. 13, pp. 376-379, 2014.

[21] W. T. Li, Y. Q. Hei, H. Subbaraman, X. W. Shi, and R. T. Chen, "Novel printed filtenna with dual notches and good out-ofband characteristics for UWB-MIMO applications," IEEE Microwave and Wireless Components Letters, vol. 26, no. 10, pp. 765-767, 2016.

[22] Y.-Y. Liu and Z.-H. Tu, "Compact differential band-notched stepped-slot UWB-MIMO antenna with common-mode suppression," IEEE Antennas and Wireless Propagation Letters, vol. 16, pp. 593-596, 2017.

[23] W. Wu, B. Yuan, and A. Wu, "A quad-element UWB-MIMO antenna with band-notch and reduced mutual coupling based on EBG structures," International Journal of Antennas and Propagation, vol. 2018, Article ID 8490740, 10 pages, 2018.

[24] N. K. Kiem, H. N. B. Phuong, and D. N. Chien, "Design of compact $4 \mathrm{x} 4$ UWB-MIMO antenna with WLAN band rejection," International Journal of Antennas and Propagation, vol. 2014, Article ID 539094, 11 pages, 2014.
[25] V. S. D. Rekha, P. Pardhasaradhi, B. T. P. Madhav, and Y. U. Devi, "Dual band notched orthogonal 4-element MIMO antenna with isolation for UWB applications," IEEE Access, vol. 8, pp. 145871-145880, 2020.

[26] K.-L. Wong, Y.-C. Chen, and W.-Y. Li, "Four LTE low-band smartphone antennas and their MIMO performance with user's hand presence," Microwave and Optical Technology Letters, vol. 58, no. 9, pp. 2046-2052, 2016.

[27] H. Sakli, C. Abdelhamid, C. Essid, and N. Sakli, "Metamaterial-based antenna performance enhancement for MIMO system Applications," IEEE Access, vol. 9, pp. 38546-38556.

[28] J. Choi, W. Hwang, C. You, B. Jung, and W. Hong, "Fourelement reconfigurable coupled loop MIMO antenna featuring LTE full-band operation for metallic-rimmed smartphone," IEEE Transactions on Antennas and Propagation, vol. 67, no. 1, pp. 99-107, 2019.

[29] S. Blanch, J. Romeu, and I. Corbella, "Exact representation of antenna system diversity performance from input parameter description," Electronics Letters, vol. 39, no. 9, pp. 705-707, 2003.

[30] F. A. Almalki, M. C. Angelides, and M. Angelides, "An enhanced design of a 5G MIMO antenna for fixed wireless aerial access," Cluster Computing, 2021.

[31] S. M. A. Capobianco, D. E. Anagnostou, R. M. Shubair, and B. D. Braaten, "A compact CSRR-enabled UWB diversity antenna," IEEE Antennas and Wireless Propagation Letters, vol. 16, pp. 808-812, 2017.

[32] R. Mark, N. Rajak, K. Mandal, and S. Das, "Metamaterial based superstrate towards the isolation and gain enhancement of MIMO antenna for WLAN application," AEU-Int J Electron C, vol. 100, pp. 144--152, 2019. 